\title{
Production of Secondary Metabolites and its Antibacterial and Antioxidant Activity During the Growth Period of Endophytic Fungi Isolated from Gall Rust Sengon Plants
}

\author{
Alfi Rumidatul' ${ }^{1}$, Noor Rahmawati ${ }^{1{ }^{1 *},}$, Sopandi Sunarya ${ }^{1}$
}

\section{Alfi Rumidatul' ${ }^{1}$, Noor \\ Rahmawati $^{1, *}$, Sopandi Sunarya ${ }^{1}$ \\ 'School of Life Sciences and Technology, Institut Teknologi Bandung, Jalan Ganesha 10 Bandung 40132, West Java, INDONESIA. \\ Correspondence \\ Noor Rahmawat \\ School of Life Sciences and Technology, Institut Teknologi Bandung, Jalan \\ Ganesha 10 Bandung 40132, West Java, INDONESIA. \\ E-mail: rahmawati@sith.itb. ac.id \\ History \\ - Submission Date: 31-10-2020; \\ - Review completed: 12-11-2020; \\ - Accepted Date: 04-12-2020}

DOI : 10.5530/pj.2021.13.42

Article Available online

http://www.phcogj.com/v13/i2

\section{Copyright}

(C) 2021 Phcogj.Com. This is an openaccess article distributed under the terms of the Creative Commons Attribution 4.0 International license.

\begin{abstract}
Introduction: In our previous study, secondary metabolites of endophytic fungi isolated from gall rust sengon showed their bioactive activity against antibacterial and antioxidant, but only gave little effect to antifungal activity. Endophytic fungal culture extracted from gall rust of sengon (Falcataria moluccana Miq. Barneby and J. W. Grimes) has the ability on inhibiting Bacillus subtilis, Pseudomonas aeruginosa and Escherichia coli. To increase the production of bioactive compounds, this research was focused on isolates which produced the highest activity compounds, and sought the optimal fermentation conditions in the production of bioactive compounds. Methods: The fermentation process was carried out on PDB liquid media for 21 days, under shaker conditions, at room temperature, and sampling measurements were hold every 3 days. Bioassay were carried out against $B$. subtilis, P. aeruginosa, and $E$. coli. Results: The early stages fungal growth was adaptation stage, continued by $1-6^{\text {th }}$ days of exponential growth period. Day 6-12 ${ }^{\text {th }}$ was stationary growth and day $15-21^{\text {th }}$ were cell death periode. The highest secondary metabolite production was achieved at stationary periodes, that was occured at days 9-15 ${ }^{\text {th }}$, and high antibacterial activity was produced on days $9-12^{\text {th }}$. Conclusion: The best production secondary metabolite that has high activity was at day $9-12^{\text {th }}$ Key words: Endophytic fungi, Secondary metabolite, Antibacteri, Antioxidant, Gall rust.
\end{abstract}

\section{INTRODUCTION}

Innovation of natural products for antibiotics and antioxidants is very urgent, because the emergence of antibiotic-resistant microorganisms that require inventive research and development strategies. Endophytic fungus isolated from the gall rust of $F$. moluccana have the ability to produce antimicrobial compounds and antioxidants. Thirty-four endophytic fungi were isolated from the gall rust of the F. moluccana, screened and evaluated for their ability to produce antimicrobial and antioxidants compounds. Antimicrobial activity was found in at least one or more pathogenic microbes (bacteria and fungi) tested. Endophytic fungal culture extract from the gall rust of the F. moluccana has the ability to inhibit B.subtilis, P. aeruginosa and E. coli. ${ }^{1}$ To further increase the production of bioactive compounds, this research is focused on isolates which in the previous studies produced the highest compound and high activity, and sought optimal fermentation conditions in production.

Endophytic fungi are microorganisms living inside plants and are considered a promising source of novel and natural biologically active compounds. ${ }^{2}$ Endophytic fungi could be found in every plant, because no studies had shown the presence of plant species without endophytes. High species diversity was another characteristic of endophytic microbes. The production of secondary metabolites in fungi can be affected by medium composition, $\mathrm{pH}$, temperature, agitation, and lighting. ${ }^{3}$ According to Deduke et al. ${ }^{4}$ the factors affecting secondary metabolite production in fungi are geographical factors, dehydration, lighting, drought, growth medium, nutrient availability, $\mathrm{pH}$, genes expression and carbon sources. Optimization of antioxidant compound production was carried out to obtain optimum condition for endophytic fungal growth which could produce secondary metabolite with bioactive compound having high antioxidant activity. Biosynthesis of secondary metabolites was directly related to culture conditions and length of incubation time, including biomass present in the production phase and duration of incubation. ${ }^{5}$ Suitable growth conditions strongly supported the production of secondary metabolites in endophytic fungi. Secondary metabolites were a kind of compound that was produced or synthesized in cells at a certain growth or stress level. These compounds were produced in little amounts to defend themselves from their habitats threat, and did not play a major role in primary metabolic processes. To achieve this aim, optimum environmental conditions were required for the growth of endophytic fungi and the production of secondary metabolites, especially antioxidant compounds.

\section{MATERIAL AND METHODS}

\section{Place and time}

The study was conducted at the microbiology laboratory of the ITB Bioscience and Biotechnology Research Center, and was held from January October 2019.

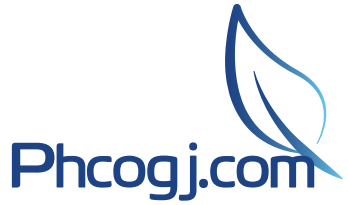

Cite this article: Rumidatul A, Rahmawati N, Sunarya S. Production of Secondary Metabolites and its Antibacterial and Antioxidant Activity During the Growth Period of Endophytic Fungi Isolated from Gall Rust Sengon Plants. Pharmacog J. 2021;13(2): 325-31. 


\section{Materials}

The materials used in this study was a gall rust tumor from the sengon plant obtained from ITB Jatinangor campus. Other materials used were Nutrient Agar (NA), Nutrient Broth (NB), Potato Dextro Agar (PDA), Potato Dextrose Broth (PDB), gram-positive bacteria (Bacillus subtilis ATCC6633), gram-negative bacteria (Pseudomonas aeruginosa ATCC9027 and Escherichia coli ATCC8939). Organic solvent that were used in this research was ethyl acetate. DPPH was used as a source of radical for antioxidan activity test.

\section{Isolation of endophytic fungi}

Isolation of endophytic fungi was carried out as follows: endophytic fungi isolated from gall rust tumors from Sengon Plant. Gall was cut approximately $1 \mathrm{~cm}$ long and rinsed with distilled water for surface sterilization and then sequentially washed with $70 \%$ ethanol (1 minute), $5.25 \%$ sodium hypochlorite (15 minutes) and rinsed again with $70 \%$ ethanol for 1 minute followed by rinsing with sterille aquadestilata (three times). Gall was cut in the middle and then placed on PDA medium which had been added with antibiotics $(200 \mu \mathrm{g}$ of chloramphenicol) and incubated at $28^{\circ} \pm 1^{\circ} \mathrm{C}$ (room temperature) for about 1-3 weeks. The mycelium derived from the sample specimens was purified and cultured under the same conditions. ${ }^{6}$

\section{Fermentation and extraction of endophytic fungi}

The fungal endophytes were cultivated on (PDB) by placing 4 agar blocks of pure culture ( $10 \mathrm{~mm}$ in diameter) of actively growing culture in $250 \mathrm{ml}$ erlenmeyer flasks containing $100 \mathrm{ml}$ of the medium. The flasks were incubated in shaker condition for 3 weeks at (21 days) $27 \pm 1^{\circ} \mathrm{C}$. The culture was filtered through filter paper to remove the mycelial mats. The liquid broth was collected and extracted with equal volume of ethyl acetate $l$ in a separating funnel by vigorous shaking for 1hour. The cell mass was separated and weight to obtain weight of micellium. The solvent was evaporated and the resultant compound was dried with $\mathrm{MgSO} 4$ and concentrated to yield the crude extracts. The crude extracts were then dissolved in methanol for antibacterial bioassay and antioxidant test. ${ }^{6}$

\section{Antioxidants activity test (2,2-Diphenyl-1-pikrilhidrazil (DPPH) Scavenging Tests)}

DPPH radical scavenging test was carried out as described by Miliauskas et al. ${ }^{7}$ with a little modification. Extracts samples $(300 \mu \mathrm{l})$ at different concentrations was added to $250 \mu \mathrm{LPPH}(1 \mathrm{mM})$. After reacting for 30 minutes, the absorbance was read at $517 \mathrm{~nm}$. DPPH radical scavenging was calculated using the following equation: DPPH radical scavenging $(\%)=[(\mathrm{A} 1-\mathrm{A} 2) / \mathrm{A} 1] \times 100$ where $\mathrm{A} 1$ is the absorbance of the control (containing all the reagents except sample extract), and A2 is the absorbance of reagen and the sample extract. ${ }^{6}$

\section{Antibacterial bioassay}

Ethyl acetate extracts from endophytic fungal culture were individually tested against panels of disease-causing microorganisms including gram-positive bacteria (B. subtillis ATCC6633) and gram-negative bacteria (P. aregunisa ATCC 9027 and E. coli ATCC8939). The inhibitory effect of extracts obtained from endophytic fungal culture on bacteria was tested by paper disc method. Disc paper $(10 \mathrm{~mm}$ in diameter) was dipped in a solution of endophytic microbial culture extract with a concentration of $10 \mathrm{mg} / \mathrm{mL}$ (dry residue /volume of methanol), then dried and placed on NA medium for bacteria to be tested. The amount of inhibitory activity of endophytic fungi culture extracts against pathogenic microbes was assessed by measuring the diameter (in $\mathrm{mm}$ ) of the zone of inhibition relative to positive and negative controls. Chloramphenicol were used as a positive control in treatment with pathogenic bacteria, while for negative controls methanol was used.
Four disc paper replications were used on each petri disk. Petri dishes that had been inoculated with fungi and bacteria were incubated at 27 ${ }^{\circ} \mathrm{C}$ for 24 hours for clinical bacterial strains, antimicrobial activity was evaluated by measuring the clear zone of the test organism. Each test in this experiment was repeated three times. ${ }^{8}$

\section{RESULTS AND DISCUSSION}

\section{Fermentation and extraction of endophytic fungi}

In previous study, we successfully isolated 34 endophytic fungi from gall rust sengon. The best three isolate from 34 isolates obtained from gall rust sengon were identification as Fusarium sp A, Fusarium sp A and Fusarium sp C.

Identificatioan was carried out molecularly. The large number of isolates of endophytic fungi that can be isolated from gall rust sengon reinforce the results of Strobel and Deasy studies suggesting that all plants found are harbors of some endophytic fungi. ${ }^{2}$ All endophytic fungi have many different functions for plants as a consequence of mutualistic symbiosis between endophytic fungi and plants. The abundance of the composition of the endophytic fungi community was strongly influenced by environmental factors (temperature and humidity), chemical variation, anatomy and maturity of the colonized host organ. ${ }^{9}$

How the endophytic fungus could enter the host plant without causing the disease symptoms, could be explained by Sieber ${ }^{10}$, who explained that the initial step of endophytic fungi went into the host plant was through recognition, germination and penetration. A similar process was also experienced by infections of plant pathogenic fungi. Along the path of the process, endophytic fungi must overcome the defense mechanism of the plant. Spores of fungi often recognized host plants through molecules such as lectins. After germination, the fungus would penetrate into the plant tissue by softening the cuticle and epidermal cell wall or damaging the cuticle with mechanical strength. Once the fungus could penetrate into the plant tissue, and it would change to a latent state, the host's defense mechanisms were no longer activated. This phenomenon was explained by the Gene-for-Gene (GFG) model, in which the avirulence genes (AVR) of the endophytes were encoded into an elicitor and recognized by the product of the resistance gene (R) of the host plant as well as the hypersensitive reaction of the host plant and then the serenity the next occurs through the signal transduction path. Instead, in pathogenic fungi did not contain the AVR gene, thus product $\mathrm{R}$ was not produced and symptoms of the disease would develop. ${ }^{10}$

The interaction of endophytic fungi with host plants resulted in a compromise between mutualism and antagonism to create a harmonious symbiotic system. Plants could limit the growth of endophytes, and thus endophytes could use various mechanisms to survive. Endophytes not only described some plant metabolites with exoenzymes to take important nutrients and energy to survive, but also produced beneficial compounds and /or support or promote the growth of host plants to achieve a balanced environment. ${ }^{1}$

The isolated of endophytic fungi were also grown on PDB medium ( $\mathrm{pH}$ 5.5), temperature $28 \pm 2{ }^{\circ} \mathrm{C}$, shaking condition for 21 days to determine mycelium growth. Dry weight of mycelium was used as a parameter of endophytic fungal growth. The growth of the mycelium of endophytic fungi during 21 days fermentation could be seen in Figure 1. This data showed that the endophytic fungi isolated from gall rust can grow well in the PDB medium, so it was hoped that they also produced secondary metabolite well.

The growth curve graph shows that the initial stage of growth is still at an adaptation level so that exponential growth starts on day 3 and reaches a maximum at H6. Static conditions were found in $\mathrm{H} 6$ - H12 and began to decrease in $\mathrm{H} 15$ to 21 . Growth curves are measured by 


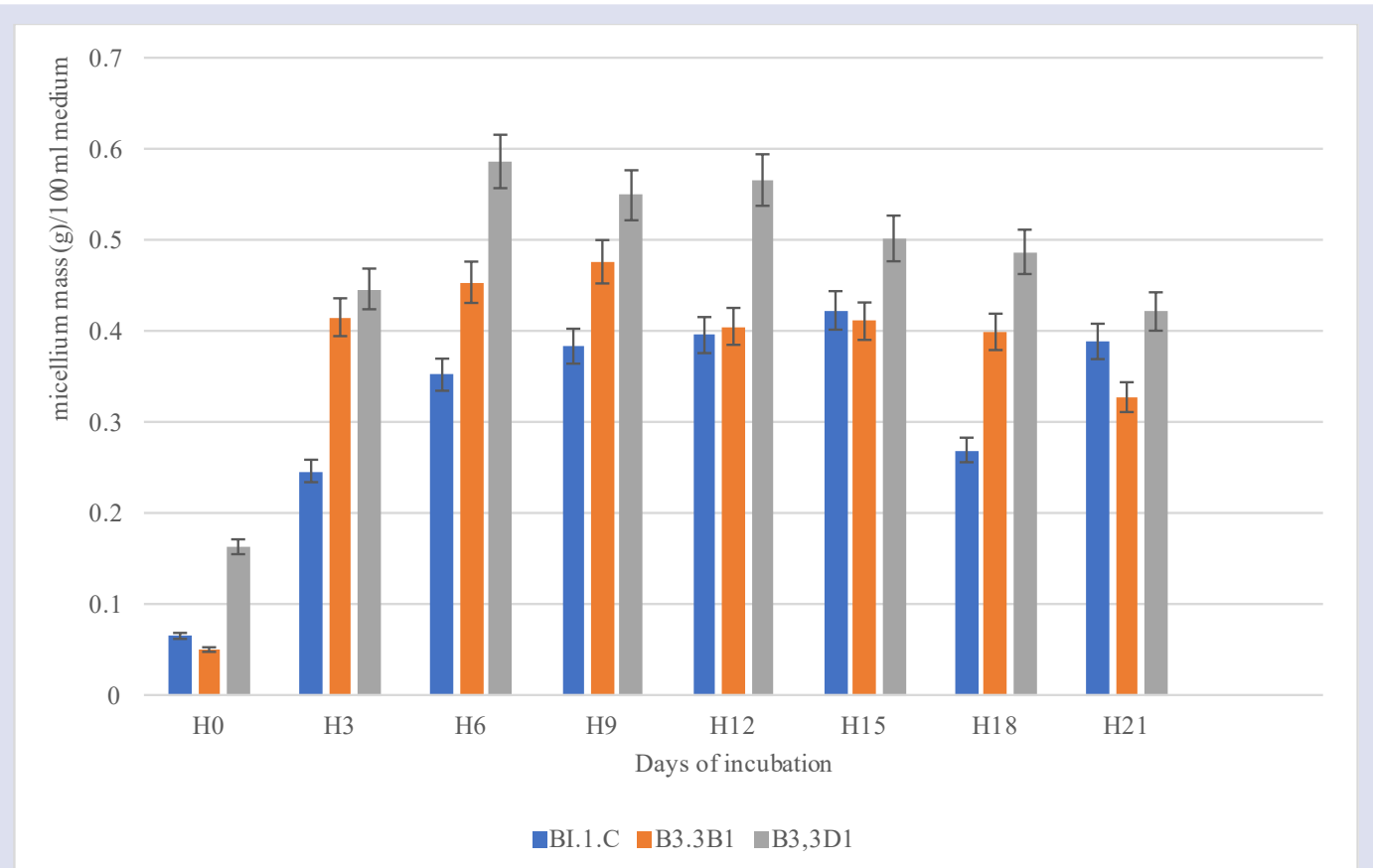

Figure 1: The growth curve of endophytic fungi from gall rust $F$. moluccana (B11C: Fusarium sp A, B33B1: Fusarium sp B, B33D1: Fusarium sp C).

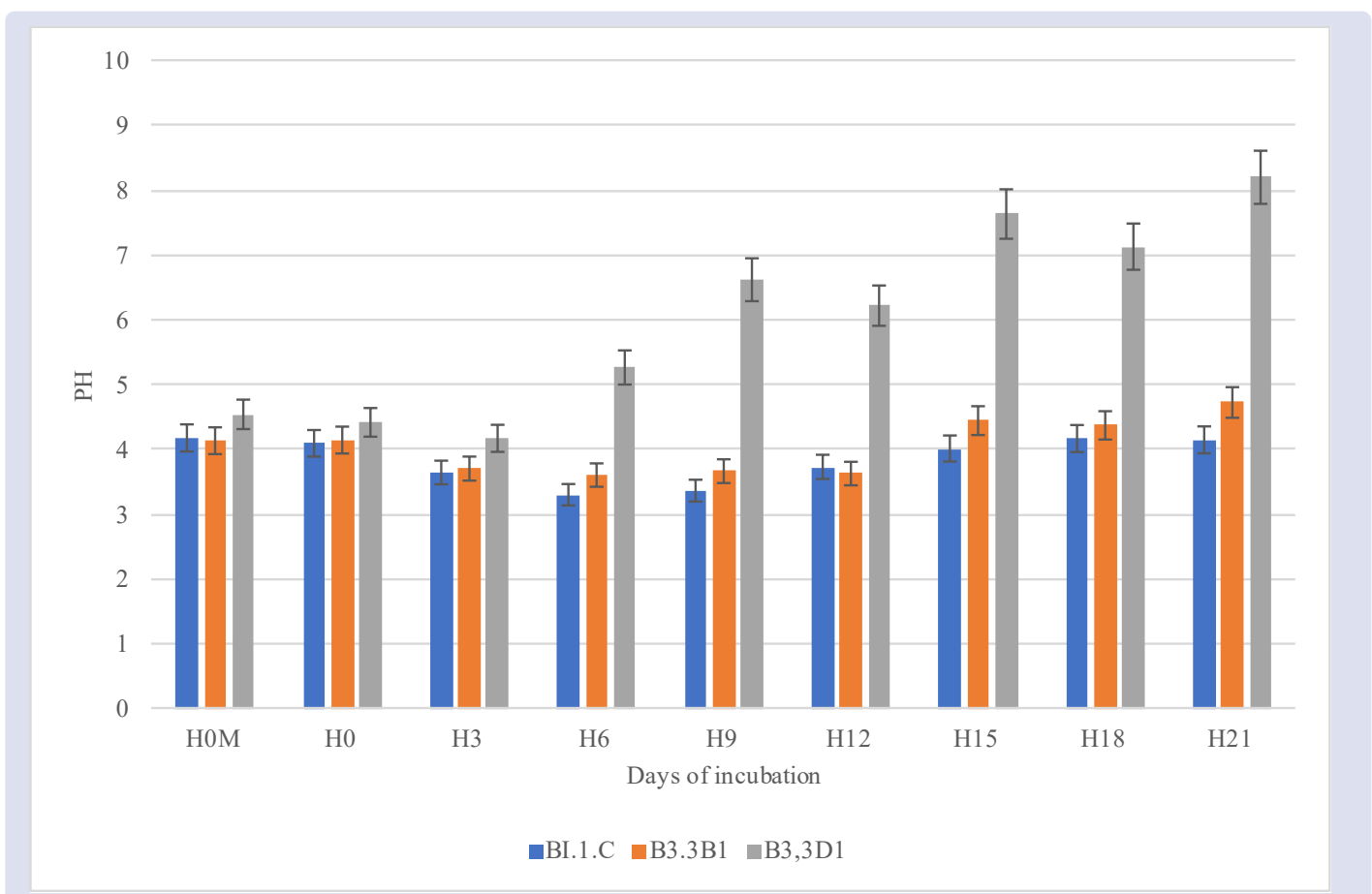

Figure 2: The change of $\mathrm{pH}$ as long as growth of fungi (B11C: Fusarium sp A, B33B1: Fusarium sp B, B33D1: Fusarium sp C).

measuring changes in mycelium weight during fermentation. At the beginning of growth the weight of mycelium is very low. When $\mathrm{H} 3$ starts to increase in mycelium weight and reaches its peak at H6, it stagnates to completion.

On day 3 it was seen that the $\mathrm{pH}$ began to decrease, this was allegedly due to the production of organic acids which could reduce the $\mathrm{pH}$ value. However, the $\mathrm{H} 15$ begins to increase in $\mathrm{pH}$ from acid to neutral. This phenomenon occurs in the 3 isolates used.
Based on the graph in Figure 3, Fusarium sp A isolate produced the highest secondary metabolite on day 15, whereas Fusarium sp C isolate the highest production was in $\mathrm{H} 12$ while $\mathrm{B} 33 \mathrm{~b}$ isolate produced the lowest secondary metabolite compared to the two other isolates. Calvo et al. ${ }^{11}$ stated that environmental factors that affect secondary metabolite production such as aflatoxin production in aspergillus fungi are $\mathrm{pH}$, carbon and nitrogen source. While Agusta ${ }^{12}$, states that suitable environmental conditions are needed for the occurrence of the sporulation process and also a determinant of the formation 


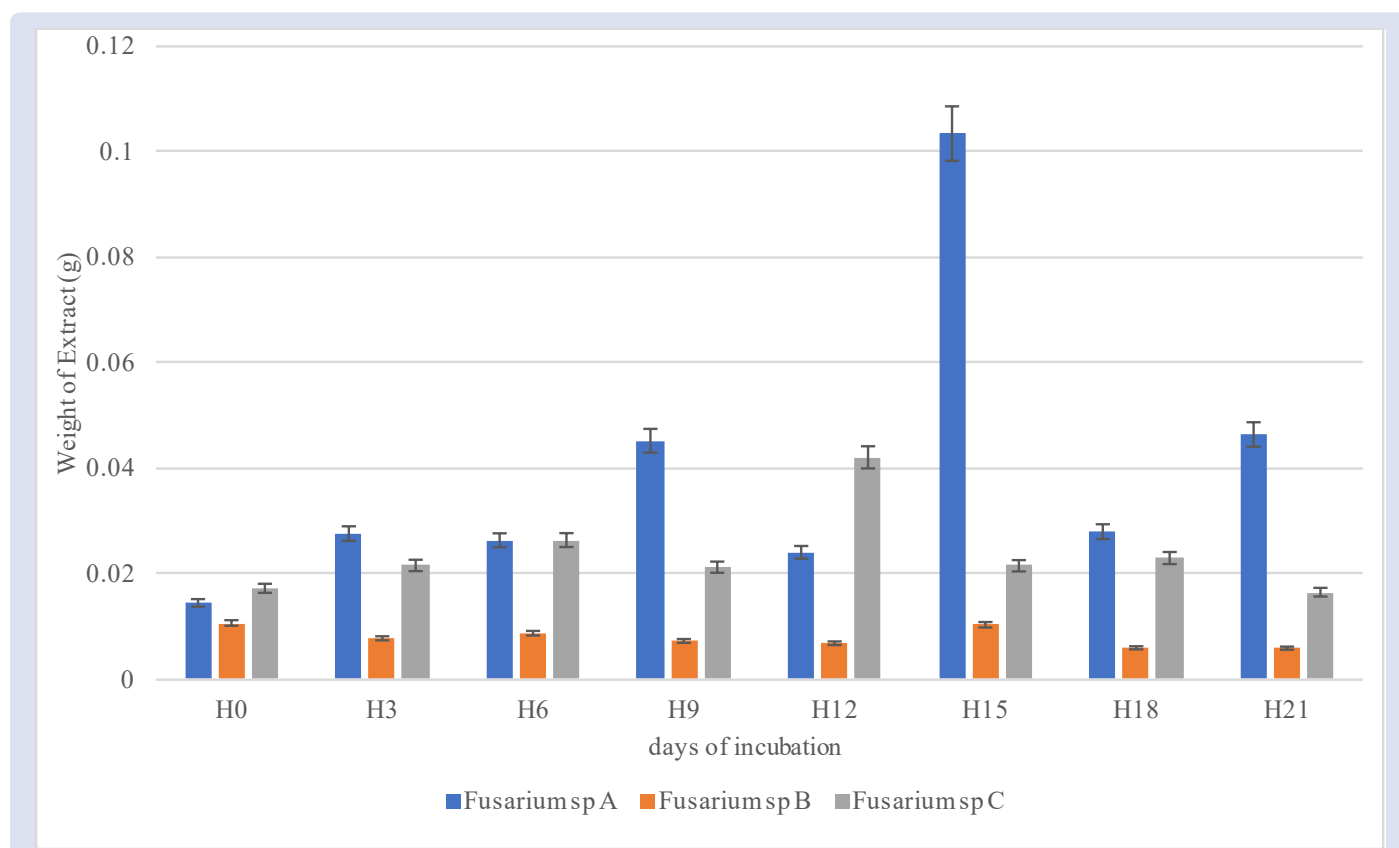

Figure 3: The curve of extraction of seconndary metabolite from endophytic fungi of gall rust F. moluccana.

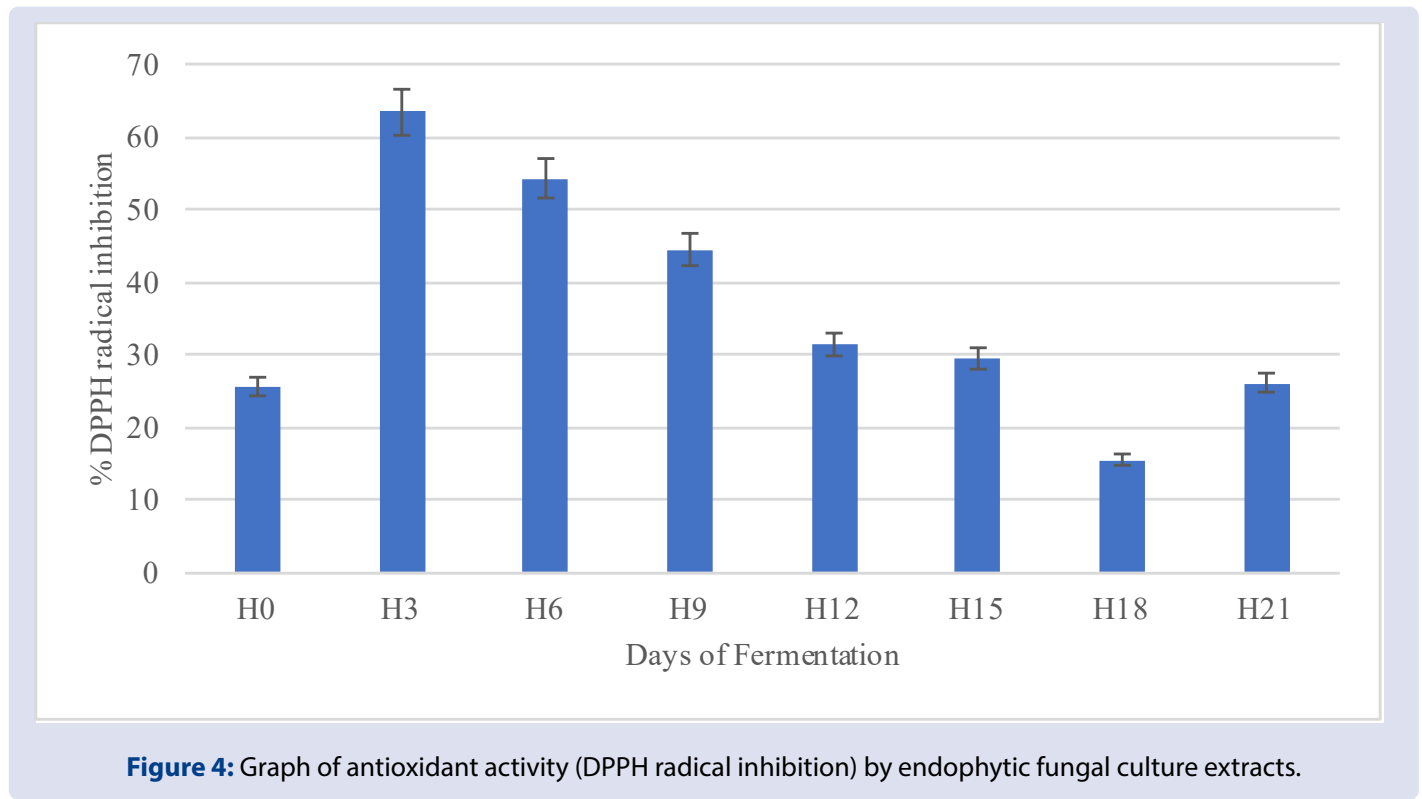

of secondary metabolites. Factors such as differences in carbon and nitrogen sources. The $\mathrm{pH}$, temperature, and concentration of salt may affect the secretion of metabolite compounds.

To determine the production of antioxidant compounds during the growth period of the endophytic fungus, a dry weight measurement of extracts from ethyl acetate solvents was used. This solvent was choosed based on previous research, that showed, among 3 solvent (methanol, ethyl acetate and $n$ hexane) that used to extrac fungal culture, ethyl acetate gave the best result. ${ }^{1}$ Ethyl acetate solvent was used as it had medium polarity so that it could dissolve polar and non polar active compounds.

\section{Antibacterial bioassay}

The methanol solvent was a polar solvent which could dissolve almost all organic compounds, even polar. semi polar. and non polar. Ethyl acetate solvents were commonly used in extracting endophytic fungal cultures. ${ }^{13}$ It was semi polar solvent, so it could extract the components contained in the fungal culture.

Table 1 shows that the antibacterial activity of the 3 endophytic fungi isolates against the 3 test bacteria was not the same. The highest inhibitory activity of B. subtillis ATCC6633 bacteria by B33d 2 Fusarium sp C isolates was highest in $\mathrm{H} 15$, although $\mathrm{H} 3$ also showed a fairly high bacterial inhibitory activity. Antibacterial activity of ethyl acetate extract from B33d2 Fusarium sp C.

All the endophytic fungi of the gall rust sengon were fermented at PDB medium and the crude, $\mathrm{EtOH}$ extract were tested for the antimicrobial activity. Antimicrobial activity of the EtOH extract of the fungal fermentation broth at a concentration of $10 \mathrm{mg} / \mathrm{mL}$ was conducted by way of agar diffusion method against a panel of target pathogenic microorganisms, including Gram-positive (B. subtilis 
Rumidatul, et al:: Production of Secondary Metabolites and its Antibacterial and Antioxidant Activity During the Growth Period of Endophytic Fungi Isolated from Gall Rust Sengon Plants

Table 1: Inhibitory activity of 3 bacteria used (B. subtilis ATCC6633, P. Aeruginosa ATCC9027, and E. coli ATCC8939).

\begin{tabular}{|c|c|c|c|c|c|c|c|c|c|}
\hline \multirow[t]{2}{*}{ Days } & \multicolumn{3}{|c|}{ B. subtilis ATCC6633 (mm) } & \multicolumn{3}{|c|}{ P. aeruginosa ATCC9027 (mm) } & \multicolumn{3}{|c|}{ E. coli ATCC8939 (mm) } \\
\hline & Fusariun sp $A$ & Fusarium sp B & Fusarium sp C & Fusarium sp $A$ & Fusarium sp B & Fusarium sp C & Fusarium sp $A$ & Fusarium sp B & Fusarium sp C \\
\hline $\mathrm{Ho}$ & 0 & 0 & 0 & 0 & 0 & 0 & 0 & 0 & 0 \\
\hline $\mathrm{H} 3$ & 10 & 5 & 27 & 10 & 10 & 15 & 27.5 & 10 & 0 \\
\hline H6 & 10 & 6.7 & 27 & 10 & 20 & 18.3 & 30 & 15 & 20 \\
\hline H9 & 10 & 15 & 27 & 10 & 10 & 26.7 & 30 & 15 & 20 \\
\hline $\mathrm{H} 12$ & 10 & 12.5 & 27 & 10 & 10 & 18.3 & 25 & 12.5 & 30 \\
\hline H15 & 10 & 15 & 30 & 10 & 10 & 15 & 17.5 & 10 & 30 \\
\hline $\mathrm{H} 18$ & 15 & 13 & 30 & 10 & 10 & 23.3 & 15 & 10 & 30 \\
\hline $\mathrm{H} 21$ & 15 & 10 & 30 & 10 & 10 & 20 & 15 & 10 & 30 \\
\hline Chloram & 30 & 30 & 30 & 30 & 30 & 30 & 30 & 30 & 30 \\
\hline Methanol & 0 & 0 & 0 & 0 & 0 & 0 & 0 & 0 & 0 \\
\hline
\end{tabular}

ATCC6633), Gram-negative bacteria (P. aeruginosa ATCC9027 and E. coli ATCC8939). Methanol was used as negative control, while chlorampenicol (100 lg/disk) as positive control, was used as standard antibacterial agents, respectively. Inhibition zones in diameter were measured to assess antimicrobial activity. Each inhibitory experiment was replicated three times.

Endophytic fungi living asymptomatically in plant tissues have also been recognized as a repository of novel secondary metabolites for potential therapeutic use. In this study we have demonstrated that crude extracts from the culture broth of endophytic fungi grown on PDB medium displayed considerable antimicrobial activity against a panel of microbe tested. Ethyl acetate extract from endophytic fungi culture tested on B. subtilis ATCC6633, P. aeruginosa ATCC9027 and E. coli ATCC 8939 bacteria showed the highest anti-bacterial inhibition compared to methanol extract and hexane extract.

\section{Antioxidant activity}

The highest DPPH inhibitory activity was found in $\mathrm{H} 3$ fermentation. The longer the fermentation time the antioxidant activity will decrease. The method commonly used to test antioxidant activity is by using a stable free radical diphenilpycrylhydrazil (DPPH). DPPH method is chosen because it is easy, fast, sensitive and requires only a small sample extract. DPPH compounds are free radicals that are stable and active by delocalizing free electrons in a molecule so that the molecule is not reactive as other free radicals. This delocalisation process is indicated by the presence of concentrated violet which can be characterized in absorbance bands in ethanol solvents at a wavelength of $517 \mathrm{~nm} .{ }^{14}$ In this method, DPPH solution which acts as a free radical will react with antioxidant compounds so that DPPH will turn into diphenilpycrilhydrazine which is non-radical. The parameters for interpreting the test results from the DPPH method are generally made in the form of Concentration $50\left(\mathrm{IC}_{50}\right)$, which is defined as the concentration of the substrate solution or the sample which will reduce $\mathrm{DPPH}$ activity by $50 \%$. The greater the $\mathrm{IC}_{50}$ value, the smaller the value of antioxidant activity. An antioxidant compound is declared good if the $\mathrm{IC}_{50}$ value is getting smaller. Antioxidant compounds are said to be very strong if they have $\mathrm{IC}_{50}$ values of less than $0.05 \mathrm{mg} / \mathrm{mL}$, strong for $\mathrm{IC}_{50}$ between $0.05-0.10 \mathrm{mg} / \mathrm{mL}$, moderate for $\mathrm{IC}_{50}$ between $0.10-0.15$ $\mathrm{mg} / \mathrm{mL}$ and weak if $\mathrm{IC}_{50}$ is worth between $0.150-0.20 \mathrm{mg} / \mathrm{mL}{ }^{14}$

Endophytic fungi isolated from gall rust were screening for antioxidant activity to know the potential of the fungi to produce antioxidant compound that inhibited free radicals. The methanol extract of endophytic culture of gall rust from sengon inhibited DPPH radical $45 \%$, meanwile ethtyl acetate extract inhibited DPPH radicals $71.5 \%$ and $\mathrm{n}$ hexane extract inhibited $28 \%{ }^{1}$ Screening endophytic fungi from Surian resulted several isolate that potential to produce antioxidant compound, like endophytic fungi from stemand from twigs and leaves of surian. ${ }^{15}$ Methanol, ethyl acetate and $\mathrm{n}$ hexane extract from bark and stem of sengon, and gall rust sengon had high antioxidant activity. ${ }^{16}$

Secondary metabolites from endophytic fungi can play a role in plant defense, and some to have pharmaceutical potential. Antioxidant efficacy cannot be comprehensively predicted with only a single antioxidant assay ${ }^{17}$, but the DPPH assay is one of the most commonly used methods to evaluate free radical scavenging activity. DPPH is a stable radical that produces a purple solution in methanol. The antioxidant activity in this study was measured by the discoloration to yellow as the stable molecule 2,2-diphenyl-1-hydrazine formed. Antioxidant compounds can scavenge the radicals by donating their hydrogen ${ }^{18}$, and the hydroxyl group of the isolated compounds may play a role in the activity. In the DPPH radical scavenging assay, antioxidants donate an electron or hydrogen radical to the DPPH radical to become a stable molecule causing discoloration of the DPPH radical. ${ }^{19}$ Endophytic fungi from E. sylvestris, Pseudocercospora sp. ESL 02 showing the highest antioxidant activity with the antioxidant compound Terreic acid (1) and 6-methylsalicylic acid (2), with terreic acid having strong antioxidant activity. The study also complements the study of the antioxidant potency of E. sylvestris as the host plant of the fungus. ${ }^{20}$

Ethyl acetate extract culture of endophytic fungi Aspergilus. niger and Alternaria. alternate isolated from different organs of Tabebuia argentea showed an antioxidant capacity of 4.299 - $5.276 \mathrm{umol} / \mathrm{L}$ and total phenol of $2.5-2.6 \mathrm{mg} / 100 \mathrm{~mL}$ cultures equivalent to the highest phenolic acid of endophytic fungal cultures. ${ }^{21}$ Analysis of 292 endophytic fungi isolated from 29 traditional Chinese herbs showed that the antioxidant capacity of endophytic fungal cultures was significantly correlated with the total phenol. ${ }^{22}$

In addition to the extensive research on bioactive compounds from plants, research on the biodiversity of fungal endophytes had also received much attention. Endophytic fungi may also produce other general secondary metabolites, such as adenosine, which exhibited potential 1,1-diphenyl-2-picrylhydrazyl (DPPH) radical scavenging activities, was isolated from Penicillium sp. YY-20, an endophytic fungus isolated from Ginkgo biloba. ${ }^{23}$ In the present study, the endophytic fungi from E. sylvestris were isolated and evaluated for their antioxidant potency. Furthermore, secondary metabolites having antioxidant activity were isolated and identified from the fungus that exhibited the highest antioxidant potency. This study can complement the research on the antioxidant potency of E. sylvestris as the host plant of the endophytes. ${ }^{1}$

\section{CONCLUSION}

The growth phase of endophytic fungi isolated from gall rust sengon consist of adaptation, logaritmic, stationary and death phase. Production of secondary metabolite began high at day 9 , reached the peak at day $12-15^{\text {th }}$. The best activity for antibacterial was reached at day 
Rumidatul, et al:: Production of Secondary Metabolites and its Antibacterial and Antioxidant Activity During the Growth Period of Endophytic Fungi Isolated from Gall Rust Sengon Plants

9-12. The best production secondary metabolite that has high activity was at Day 9-12.

\section{ACKNOWLEDGMENTS}

The authors would like to thank the Directorate of Research and the Community Service Directorate General of Research and Development of the Ministry of Research Technology and Higher Education Republic of Indonesia, for providing Research Grant No. 2/EI/KP.PTNBH/2019 for this research.

\section{CONFLICTS OF INTEREST}

There are no conflicts of interest.

\section{REFERENCES}

1. Rahmawati N, Sunarya S, Rumidatul A. Exploration of Potential Bioactive Compounds Of Endophytic Microbial Culture Isolated From Gall Rust Sengon (Falcataria Moluccana Miq, Barneby \& J.W Grimes). JPSR-November(S). 2018;156-69

2. Strobel GA. Endophytes as sources of bioactive products. Microbes Infect. 2003:5(6):535-44

3. Venugopalan A, Srivastava S. Endophytes as in vitro production platforms of high value plant secondary metabolites. Biotechnology Advances. 2015;33(6):873-87.

4. Deduke C, Timsina B, Pierce-Normore MD. Effect of Environmental Change on Secondary Metabolite Production in Lichen Forming Fungi. In: Young S, Editor. International Perspectives on Global Environmental Change. London: InTech, p. 197-230; 2012 .

5. Gogoi DK, Deka Boruah HP Saikia R, and Bora TC. Optimization of process parameters for improved production of bioactive metabolite by a nove endophytic fungus Fusarium sp. DF2 isolated from Taxus wallichiana of North East India. World J Microbiol Biotechnol. 2008;24(1):79-87.

6. Zeng PY, Wu JG, Liao LM, Chen TQ, Wu JZ, and Wong KH. In Vitro Antioxidant Activities of Endophytic Fungi Isolated from The Liverwort Scapania verrucos. Genetics and Molecular Research, 2011;10(4):3169-79.

7. Miliauskas G, Venskutonis PR, Van Beek TA. Screening of radical scavenging activity of some medicinal and aromatic plant extracts. Food Chemistry. $2004 \cdot 85(2) \cdot 231-37$

8. Chamkhi I, Sbabou L, Aurag J. Endophytic Fungi Isolated from Crocus sativus L. (Saffron) as a Source of Bioactive Secondary Metabolites. Pharmacog J. 2018;10(6):1143-8.
9. Sanchez AA, Oki Y, Fernandes GW, Ball RA, Gamon J. Relationships between endophyte diversity and leaf optical properties. Tress. 2012;26:291-9.

10. SieberTN. Endophytic fungi in forest trees: are they mutualistis?. Fungal Biolog Reviews. 2007:21(2-3):75-89.

11. Calvo AM, Wilson R.A, Bok JW, Keller NP. Relationship between Secondary Metabolism and Fungal Development. Microbiol Mol Biol Rev. 2002;66(3):44759.

12. Agusta A. Biologi dan Kimia Jamur Endofit. Penerbit ITB, p. 11-27, 2009.

13. Sarker SD, Nahar L, Kumarasamy Y. Microtitre plate-based antibacterial assay incorporating resazurin as an indicator of cell growth, and its application in the in vitro antibacterial screening of phytochemicals. Methods. 2007;42:321-4.

14. Rahmawati N, Isfandito AR, Astuti DI, Aditiawati, P. Endophytic fungi from surian (Toona sinensis Roem) and antioxidant potency from its culture. Asian J Plant Sci. 2016;15(1-2):8-15.

15. Molyneux P. The use of stable free radical diphenylpicrylhydrazyl (DPPH) for estimating antioksidan activity. Journal Science Technology. 2004;26(2):211-9.

16. Rumidatul A. Potensi medik metabolit tanaman sengon (Falcataria moluccana (miq) Barneby \& J.W Grimes) yang terserang penyakit karat tumor. Disertasi. Institut Teknologi Bandung: Bandung. 2018.

17. Zhao JT, Ma DH, Luo M, Wang W, Zhao C, Zu YG, et al. In vitro antioxidan activities and antioxidant enzyme activities in HepG2 cells and main active compounds of endophytic fungus from pigeon pea (Cajanus cajan (L.) Millsp.). Food Res Int. 2014;56:243-51

18. El-Haci IA, Bekkara FA, Mazari W, Gherib M. Phenolics content and antioxidan activity of some organic extracts of endemic medicinal plant Anabasis aretioides Coss. \& Moq. from Algerian Sahara. Pharmacogn J. 2013;5(3):108-12.

19. Kedare SB, Singh RP. Genesis and development of DPPH method of antioxidant assay. J Food Sci Technol. 2011;48(4):412-22

20. Prihantini Al, Tachibana S. Antioxidant compounds produced by Pseudocercospora sp. ESL 02, an endophytic fungus isolated from Elaeocarpus sylvestris. Asian Pac J Trop Biomed. 2017;7(2):110-5.

21. Sadananda TS, Nirupama R, Chaithra K, Govindappa M, Chandrappa CP, Raghavendra V. Antimicrobial and Antioxidant Activities of Endophytes From Tabebuia Argentea and Identification of Anticancer Agent (Lapachol). Journal of Medicinal Plants Research. 2011:5(16):3643-52.

22. Huang WY, Zhong CY, Jie X, Corke, Mei S. A Potential Antioxidant Resource: Endophytic Fungi from Medicinal Plants. Economic Botany. 2007;61(1):14-30.

23. Yuan Y, Tian JM, Xiao J, Shao Q, Gao JM. Bioactive metabolites isolated from Penicillium sp. YY-20, the endophytic fungus from Ginkgo biloba. Nat Prod Res. $2014 \cdot 28(4) \cdot 278-81$ 


\section{GRAPHICAL ABSTRACT}

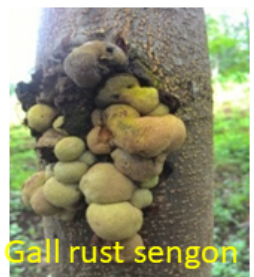

\section{SUMMARY}

The growth phase of endophytic fungi isolated from gall rust sengon consist of adaptation, logaritmic, stationary and death phase. Production of secondary metabolite began high at day 9 , reached the peak at day $12-15^{\text {th }}$. The best activity for antibacterial was reached at day $9-12$.

The best production secondary metabolite that has high activity was at Day $9-12$
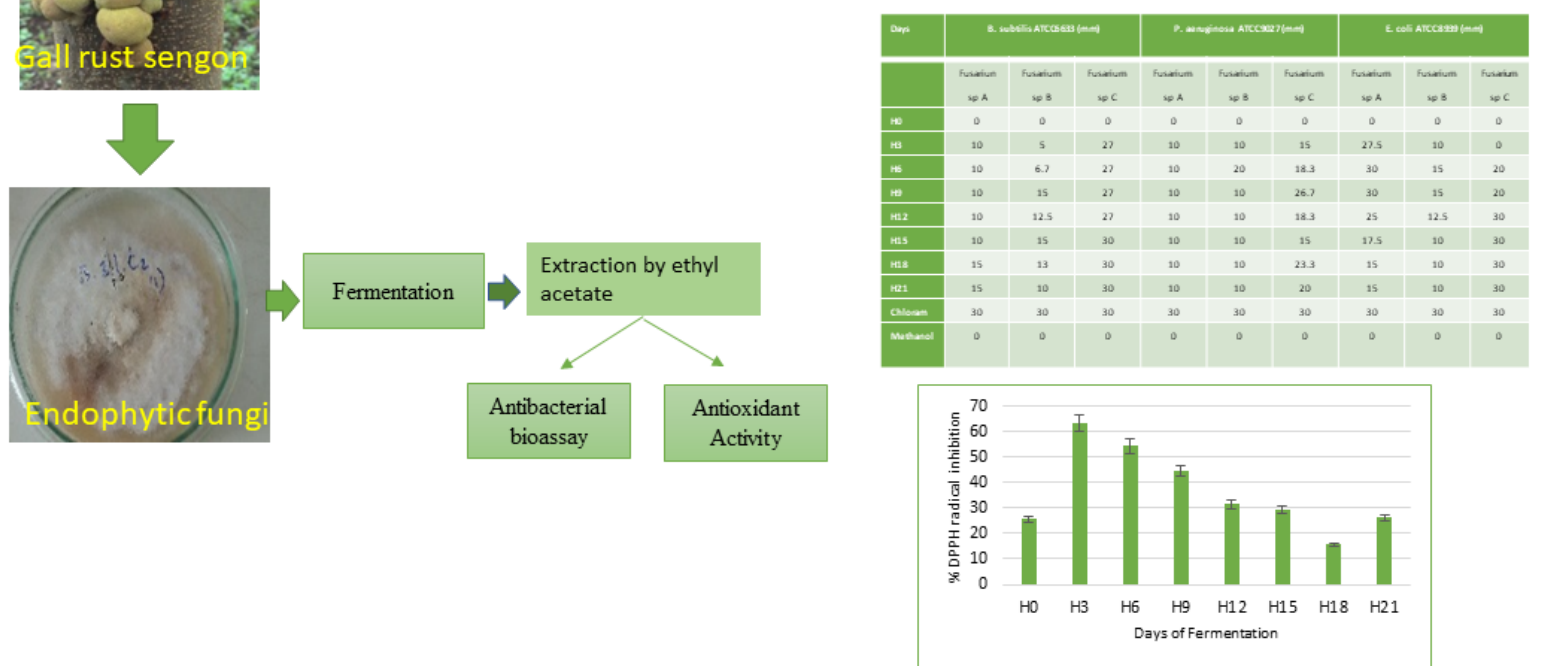

\section{ABOUT AUTHORS}

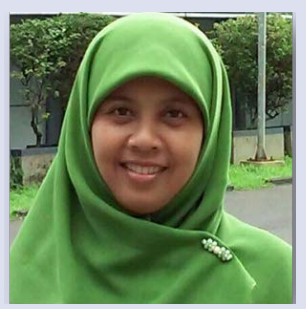

Dr. Alfi Rumidatul, S.Hut, M.Si

Lecturer at School of Life Sciences and Technology, Institut Teknologi Bandung, Indonesia, Forestry Technology Research Expertise Group. Research interest: isolation of chemical compounds of forestry plants and the testing of biological activities to see their potential as antimicrobials, anticancer, antioxidants and chemical processing of non-wood forest products.

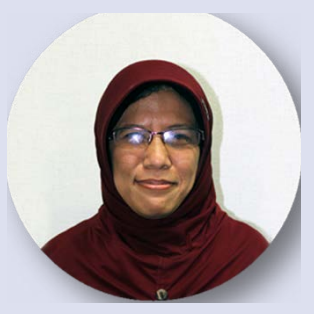

Noor Rahmawati, S.Hut, M.Si

Lecturer at School of Life Sciences and Technology, Institut Teknologi Bandung, Indonesia. Microbial Biotechnology Research Expertise Group, Research interest: isolation of endophytic microbes in forestry plants that are useful to be developed into food products, health, medicines, cosmetics, pesticides and other products.

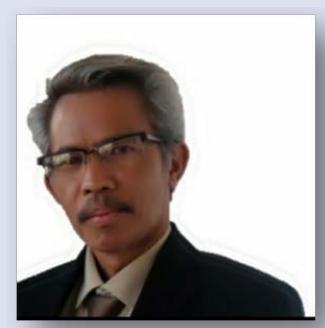

Dr. Sopandi Sunarya, S.Hut, M.Si

Lecturer at School of Life Sciences and Technology, Institut Teknologi Bandung, Indonesia, Forestry Technology Research Expertise Group. Research interest: tree improvement, forest tree seed, silviculture, agroforestry and genetics.

Cite this article: Rumidatul A, Rahmawati N, Sunarya S. Production of Secondary Metabolites and its Antibacterial and Antioxidant Activity During the Growth Period of Endophytic Fungi Isolated from Gall Rust Sengon Plants. Pharmacog J. 2021;13(2): 325-31. 